\title{
(息)
}

Citation:

Glazzard, J (2017) What Could Replace the Phonics Screening Check during the Early Years of Reading Development? FORUM, 59 (2). ISSN 0963-8253 DOI: https://doi.org/10.15730/forum.2017.59.2.175

Link to Leeds Beckett Repository record:

https://eprints.leedsbeckett.ac.uk/id/eprint/4023/

Document Version:

Article (Accepted Version)

The aim of the Leeds Beckett Repository is to provide open access to our research, as required by funder policies and permitted by publishers and copyright law.

The Leeds Beckett repository holds a wide range of publications, each of which has been checked for copyright and the relevant embargo period has been applied by the Research Services team.

We operate on a standard take-down policy. If you are the author or publisher of an output and you would like it removed from the repository, please contact us and we will investigate on a case-by-case basis.

Each thesis in the repository has been cleared where necessary by the author for third party copyright. If you would like a thesis to be removed from the repository or believe there is an issue with copyright, please contact us on openaccess@leedsbeckett.ac.uk and we will investigate on a case-by-case basis. 


\section{H) Jonathan Glazzard (2016) What could replace the phonics screening check during the early years of reading development?}

Diagnostic assessment can be a very important tool at a stage when development of skills is still insecure and incomplete. There is a clear role for it, for example, around Year 1 for many children at a particular stage in literacy acquisition. However, the assessment needs to be attuned to the needs of the learning. This article questions the universal requirement of a phonics check at the end of Year 1, and discusses more flexible alternatives.

The synthetic phonics approach introduces beginning readers to the smallest units of sound in words. Pupils learn to read words by enunciating each of the phonemes in sequence throughout a word to read the target word. This approach is often referred to as 'blending' or 'decoding'. Beginning readers are thus able to decode print regardless of whether they understand the words they are reading.

Such an emphasis on decoding is demonstrated through the introduction of the phonics screening 'check' for all pupils in Year 1 at the age of 5-6. This is a test of decoding rather than comprehension, and, in order to ensure that pupils are not reading words from memory, many of the words that are presented to children are pseudo 'non-words'. This means that the only way of identifying the target word is through enunciating the phonemes in sequence throughout the word and merging them together to identify the word.

Its imposition relates to the obsession of a government minister Nick Gibb for the synthetic phonics approach. It was designed to ensure that teachers all teach in an officially approved way. It is too inflexible to serve as a diagnostic tool to identify the learning needs of all young children.

The United Kingdom Literacy Association (UKLA 2012) recommended that the 'check' should only be used to identify development needs for individual children rather than being used with all children, on account of its holding back more able readers and potentially undermining their confidence as readers.

It does not take account of the different ways in which children acquire literacy. Although blending separate phonemes is a prime skill through which many children learn to read (Ehri 2005), many nevertheless learn to read through visual approaches (Ehri 2005; Frith 1985; Frith 1986) and some use contextual cues as a basis for word recognition rather than relying on the skill of blending (Goodman 1976). This might involve missing a word out and reading ahead to the end of a sentence before going back to identify the target word. Some children are fluent in reading by the time they take the 'check' (UKLA 2012), raising further questions about the relevance of the phonics check.

Its main feature is that it separates decoding from making sense of a text. This is a strength, if used on particular children at certain points in time, but it is also a major weakness.

\section{The Simple View of Reading}

The Simple View of Reading (SVR) was developed by Gough and Tunmer nearly thirty years ago (Gough and Tunmer, 1986). The model proposes that reading ability or reading comprehension ( $\mathrm{R}$ ) is the product of two components; decoding (D) and language comprehension (C). The model suggests that the two components are independent of each other and that each is necessary for successful reading (Gustafson et al. 
2013). Thus, neither decoding nor language comprehension is sufficient in itself to produce skilled and effective reading.

However, the extent to which decoding and comprehension predict reading ability is dependent upon the level of reading skills. For children who are struggling readers, decoding is a better predictor of reading ability; but comprehension is a better predictor to explain variance in reading ability among skilled readers (Hoover and Gough 1990). Thus, for struggling readers, the phonics screening check may be useful as a predictor of their development in the skill of word recognition (decoding). However, for children who are already fluent readers, the check is not appropriate because they have already mastered the skill of word recognition. For these readers, we need to know more about their skills in comprehension skills in order to support their subsequent reading development.

Although the Simple View of Reading is simple in the sense that it identifies only two components of reading (word recognition and language comprehension), the skills of decoding and comprehension are actually quite complex. The model thus risks over-simplifying the component skills of reading development. As word recognition develops, there is a gradual shift from phonological decoding to orthographic processing (for example, retrieving whole-word shapes from their store in the visual memory) (Gustafson et al. 2013) and skilled readers tend to use orthographic strategies rather than the phonological strategy which relies on grapheme-phoneme conversion (Ehri and Wilce 1987). Additionally, Kirby and Savage (2008) argue that fluency as well as accuracy is important in decoding, so this skill also needs to be developed.

\section{Ehri's model}

Ehri's theory of reading development (Ehri 1992; 1995) proposes four phases in the development of automatic word reading. These phases are termed: pre-alphabetic; partial alphabetic; full alphabetic and consolidated alphabetic.

In the pre-alphabetic phase, children have not yet understood the relationship between phonemes and graphemes. At this phase their reading is dependent upon visual memory (Stuart, Stainthorp and Snowling 2008). They may be able to read environmental print, especially if it appears with salient visual cues such as logos which use specific colours and fonts (Johnston and Watson 2007).

In the partial alphabetic phase, beginning readers are able to identify the initial and final phonemes in spoken words and make some connections between graphemes and their corresponding phonemes (Stuart, Stainthorp and Snowling 2008). Their attempts at decoding are not always accurate at this phase but they are no longer arbitrary.

The phonics screening check assesses children's skills against the full alphabetic stage rather than assessing whether beginning readers are operating at the pre, partial or full alphabetic phases. Thus, it fails to assess reading against a developmental framework. As such it ignores some of the earlier phases in reading development and this does not help teachers to determine appropriate forms of intervention for children whose decoding skills are not secure...

However, Ehri's model falls somewhat short in neglecting the significant role that oral language 
comprehension plays in reading development. The Simple View of Reading, on the other hand, explicitly acknowledges that word recognition alone is insufficient to produce good readers. It has been argued that: Vocabulary is one of the most consistent predictors of reading comprehension: children with good vocabularies understand texts better, and the predictive relationship between vocabulary and reading comprehension increases through the primary grades (Snow 2002; Torgesen et al. 1997).

Research suggests that, although developing the skill of decoding makes the most significant contribution for children with reading difficulties (Gustafson et al. 2013), language comprehension is the most important predictor of reading comprehension for children with typical reading development (Gustafson et al. 2013; Hoover and Gough 1990).

Despite the contribution that these models make to our understanding of reading development, the SVR fails to identify the pre-reading skills which children need for word recognition skills, and Ehri's model neglects the role of linguistic comprehension in reading development. Despite the limitations, both the SVR and Ehri's model of reading development provide the basis for more effective models of assessment than the phonics screening check.

In the case of poor readers with under-developed skills in decoding, assessing the skill of decoding (which is what the phonics screening check does) is insufficient because skilled teachers will already be aware that these children are struggling to decode print. Other means are needed of assessing whether children have an appreciation of rhyme or alliteration, whether they can substitute different initial letters while leaving the rest of the word the same, and so on. Some of these judgements can best be made informally or in playful interactions with individual children.

Given the frequency of irregular words in the most basic sentences in English, immediate recognition of words such as the, there, is, was, and so on is very important. It is these words which hold sentences together, which carry the grammar without which meaningful literacy is impossible. Unless they are easily recognised on sight, partly by perceiving the shape of the word as a whole, fluency will be impeded. Assessing such key words cannot be done through a phonics check.

The phonics screening check therefore serves little purpose, apart from serving as an accountability tool to teachers and as a mechanism for labelling children. More importantly, it can have a detrimental impact on those children who 'fail' the test and are required to re-take it the following year.

\section{Conclusion}

The phonics screening check is unhelpful in terms of informing intervention for the weakest readers and could have a detrimental impact on the progress of the most-able readers who need to develop their skills in reading comprehension. As a starting point for assessment during Year 1, teachers should use the SVR as the basis for thinking about children's skills in both word recognition and linguistic comprehension. This will broadly inform the type of intervention that is required to support a child's reading development. Those children with poor word recognition skills can then subsequently be assessed against Ehri's developmental framework to identify which phase they are working within. 
For children who are working at the pre or partial alphabetic phases, a more detailed assessment tool may be required and should include skills such as compound word blending, syllable blending, onset and rime blending, phoneme addition, phoneme deletion and phoneme substitution. As reading is also a visual process, poorer readers should also be assessed against a framework for visual skills development which includes visual attention, visual discrimination, visual memory and visual sequential memory.

|For those children who can read aloud quite fluently, using a combination of phonic decoding and recognising frequent irregular words, the teacher's attention will need to be on a growing ability to make sense of texts in a variety of genres, as well as on the range of vocabulary. Assessment might be aided by informal questions about the meaning of texts and more difficult words.

The phonics screening check fails to capture the complexity of reading development. A more detailed framework for assessment, based on theoretical models of reading development, would be more appropriate. Rather than constraining teachers through a single compulsory test, the 'phonics check', teachers' professional ability to select from a range of tools and informal approaches to assessment needs to be developed.

Much of this article was originally published in a longer article in English in Education, ... We are grateful to the editors for allowing the material to be republished. 